\title{
Housing Aspirations and Level of Housing ${ }^{1}$
}

\author{
By AIMO PULKKINEN
}

The Population Research Institute

Should a Finn decide to move, he may be faced with a number of housing alternatives. If, on the other hand, he sets himself a housing goal, he will try to become owner of his house. Very rarely, it seems, will he be ultimately content with a rented house. In speaking of his goals, he is referring to a selfowned apartment or, even more often, a small, separate house owned by him alone. ${ }^{2}$

The popularity of privately-owned housing became apparent once again in a study carried out by the Population Research Institute. This time, the results were quite clear, even though in the study the goals were tied into the costs of housing and the availability of financial resources. Of the housing possessed by the households interviewed in 1972 , already almost half $(45,1 \%)$ were privately owned. This is somewhat less than the average for the entire country, which according to the 1970 census was $57,3 \%$. When the goals were charted, the percentage of privately-owned houses rose to over four-fifths $(83,1 \%)$.

1 This paper is based on a summary of the researcher's study, on the choice of housing goals when limited by the possibilities, published in 1974 in the B-series of the Population Research Institute. This study, an investigation of the housing goals of Finns, covered the entire country and its data was composed of 1782 households $(71,9 \%$ of the sample). The age of the heads of these households varied from 18 to 65 years. The information was collected by means of a 15-page questionnaire that was sent by mail and collected by the interviewers in mid-1972. The questionnaire consisted of a total of 83 questions, 31 of which were to be answered by every respondent and which dealt with the household's present housing, plus the usual background data. The 52 other questions dealt with a possible change in housing, with the related goals. Of these questions, 36 were common to all the respondents, while the other 16 were divided by subject into one-family houses, row houses and apartments, with 4,4 and 8 questions respectively. Within the limits of their budgets, and being aware of the central cost factors of housing, the households were permitted to go into greater detail in describing what their housing goal would be. In a sense, they built their house themselves, taking into consideration on one hand their economic possibilities and ability to pay, and on the other hand the different cost factors of housing, supplied to them by the interviewer based on the average costs estimated by the Building Economics Laboratory of the State Technical Research Center. This was done in order to uncover what one was prepared to and not prepared to pay for, no matter if the goal was a privately-owned or a rented house.

2 In this paper, a »separate house» will refer to a row house or a one-family house, as opposed to an apartment house. (Translator's note). 
Only about every seventh household indicated in their plans that they would move to a rented house. These percentages are a strong confirmation of earlier research results.

Over one-half of the households seeking a privately-owned house were prepared to pay more for their housing than what they do now. On the other hand, of those moving to a rented house, three out of four will seek a lower rent than before. Housing is expensive for everyone, no matter whether he is living in a privately-owned house or a rented one. However, it seems as if a privately-owned house is a condition for a willingness to pay more. When the circumstances were otherwise, the decisions are made on a different basis.

At the same time as a Finn is seeking a privately-owned house, he seems to be seriously dreaming of a separate one. His housing goals are usually directed towards this, only to come across very common set-backs due to the present apartment-house-oriented building policy.

More and more households are beginning to get tired of apartments. ${ }^{3}$ At the moment, four out of five households are seeking a privately-owned separate house, specifically a one-family house. Row houses were also found to be

Figure 1. Housing goals according to form of housing and form of possession.

Privately owned house

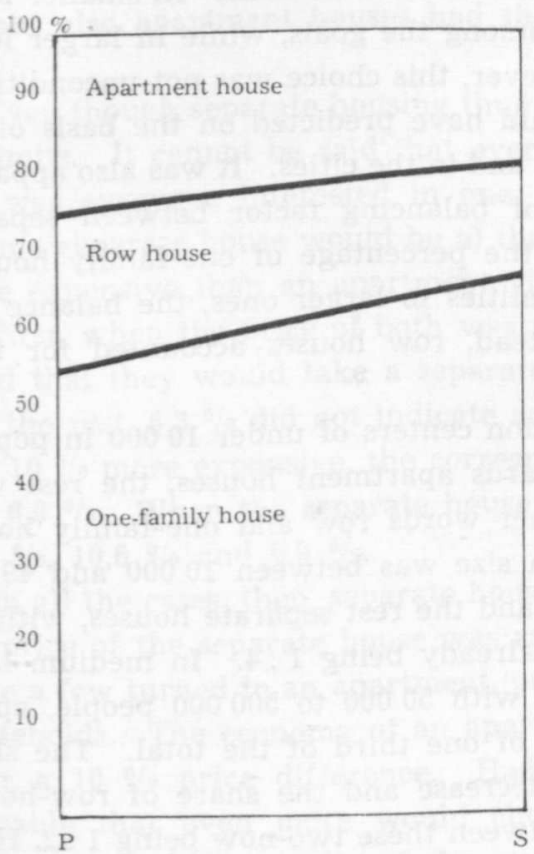

Rented house

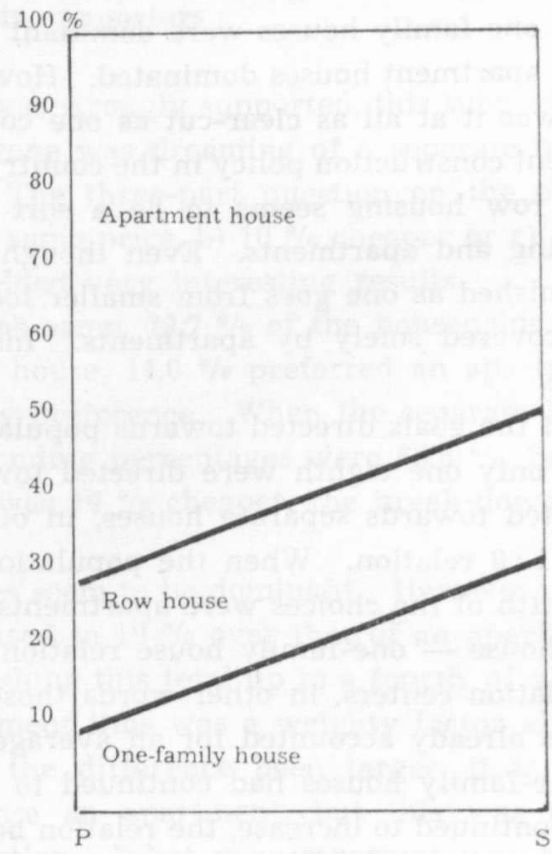

P - primary movers

S - secondary movers

3 According to the 1970 census, 56,4 \% of Finnish households were in private houses, $2,1 \%$ in row houses and $41,5 \%$ in apartment houses. 
attractive, and they were the goal of many, but one-family houses dominated these goals at the rate of $4: 1$. An average of only every fifth household would choose to live in a privately-owned apartment. Also, those households that were planning a move to a rented house were attracted by separate housing, but, probably aware of the present rented-housing market, over one half decided immediately on an apartment.

The possibilities of housing were also reflected in the decisions of the households seeking privately-owned housing. The earlier the move was supposed to take place, the more often the goal was an apartment. On the other hand, if the time of the move was still in the hazy future, the responses were dominated by the thought of separate housing. When the decision was pressed by the force of circumstances, the decision was thus understandably centered on an apartment, while those households who were not yet thinking of moving possibly believed that the future will open up possibilities of finding a separate house.

\section{Separate houses dominant, irrespective of the locale}

The size of the population center seemed to have a bearing on the form of housing, something which is quite understandable in itself. In smaller localities, one-family houses were dominant among the goals, while in larger localities, apartment houses dominated. However, this choice was not unconditional nor was it at all as clear-cut as one could have predicted on the basis of the present construction policy in the country and in the cities. It was also apparent that row housing seems to be a sort of balancing factor between separate housing and apartments. Even though the percentage of one-family housing diminished as one goes from smaller localities to larger ones, the balance was not covered solely by apartments. Instead, row houses accounted for their share.

Of the goals directed towards population centers of under 10000 in population, only one eighth were directed towards apartment houses, the rest were directed towards separate houses, in other words row and one-family houses in a $1: 9$ relation. When the population size was between 10000 and 49000 , one fifth of the choices were apartments and the rest separate houses, with the row house - one-family house relation already being 1:4. In medium large population centers, in other words those with 50000 to 500000 people, apartments already accounted for an average of one third of the total. The share of one-family houses had continued to decrease and the share of row-houses had continued to increase, the relation between these two now being $1: 2$. However, even now one-family houses were the choice of almost every other respondent. In the Helsinki area, in other words in a population center of over 500000 inhabitants, apartment houses were the most common choice, but even now their total remained under one half of all the responses. Separate houses 
remained dominant, but the relation between row houses and one-family houses had become $1: 1$.

Even though the choice tended more and more towards apartments the larger the population center, they were never dominant. It may also be that all in all it is not always solely a question of an increase in the popularity of apartments in the larger population centers. Also the limits of the possibilities in the larger population areas may affect the decisions.

Most of the separate houses were preferred as one-floor ones. All of the space in the house was supposed to be on the same level, both when it was a question of a one-family house and when it was a row house. Two-floor houses also had their supporters, but these remained in the minority. Most indicated that the separate houses should be built of wood but covered with bricks, or completely built of bricks. Only every third one-family house supporter and every fifth row house supporter wanted his house to be made solely of wood, which was the cheapest of the alternatives presented when it came to privatelyowned housing. Those who would rent their house seemed to be more unsure of the construction material than were those who wanted privately-owned housing, but they were at the same time more tolerant, as they were somewhat more willing to accept wood housing.

\section{... but also apartment houses had their supporters}

Even though separate housing thus was strongly supported, this support had its limits. It cannot be said that everyone was dreaming of a separate house, nor was everyone interested in one. The three-part question on the choice when a separate house would be a) the same price, b) $10 \%$ cheaper or c) $10 \%$ more expensive than an apartment yielded very interesting results.

First, when the price of both was the same, $79,7 \%$ of the households indicated that they would take a separate house, $14,0 \%$ preferred an apartment, and the rest, 6,3\% did not indicate any preference. When the separate house was $10 \%$ more expensive, the corresponding percentages were $68,6 \%, 24,5 \%$ and $6,9 \%$. When the separate house was $10 \%$ cheaper, the break-down was $82,5 \%, 10,6 \%$ and $6,9 \%$.

In all the cases, then, separate houses seem to be dominant. However, when the price of the separate house was raised to $10 \%$ over that of an apartment, quite a few turned to an apartment, pushing this total up to a fourth of all the households. The economy of an apartment thus was a weighty factor already after a $10 \%$ price difference. Had the difference been larger, it is quite probable that even more would choose an apartment, but this was not a central part of the results of the question. What was important was how a difference in price in favor of a separate house affected the choice.

When separate houses were presented as an alternative that was $10 \%$ cheaper than an apartment, one would suppose that this alternative would 
attract those who originally chose an apartment. Contrary to expectations, this did not occur. The percentage of those who would choose a separate house did increase to $82,5 \%$, but the increase was only 2,8 percentage points. The percentage of those who chose an apartment was still $10,6 \%$, down from $14,0 \%$, and the number of those who were not sure increased from $6,3 \%$ to $6,9 \%$. Apartments thus clearly and understandably had their own supporters, the percentage of which varied from 10,6 to 24,5 depending on the difference in price.

The ideal of the separate house was also reflected in the size of the house, or vice versa. The larger the house that was the goal, the more rarely one wanted it as an apartment. When dealing with privately-owned houses, a distinct dividing line was three rooms and a kitchen, in other words the smallest family house. When the ideal house was smaller than this, almost one out of two wished for a separate house. When the ideal house was this size or larger, the difference became even more marked, and became more so with an increase in size. The majority of those who wished for this small family house - more than four out of every five - wanted a separate house, specifically a one-family house. The relation between row houses and onefamily houses at this house size was, on the average, $1: 4$, and this relation remained about the same with houses one room larger. With even larger houses, the relation grew to 1:3. Of those households having as their goal four rooms and a kitchen, only an average of every tenth would choose an apartment. When the size of the house was even larger, only four households out of every hundred would take an apartment.

Figure 2. Housing goals according to form of housing and number of rooms.

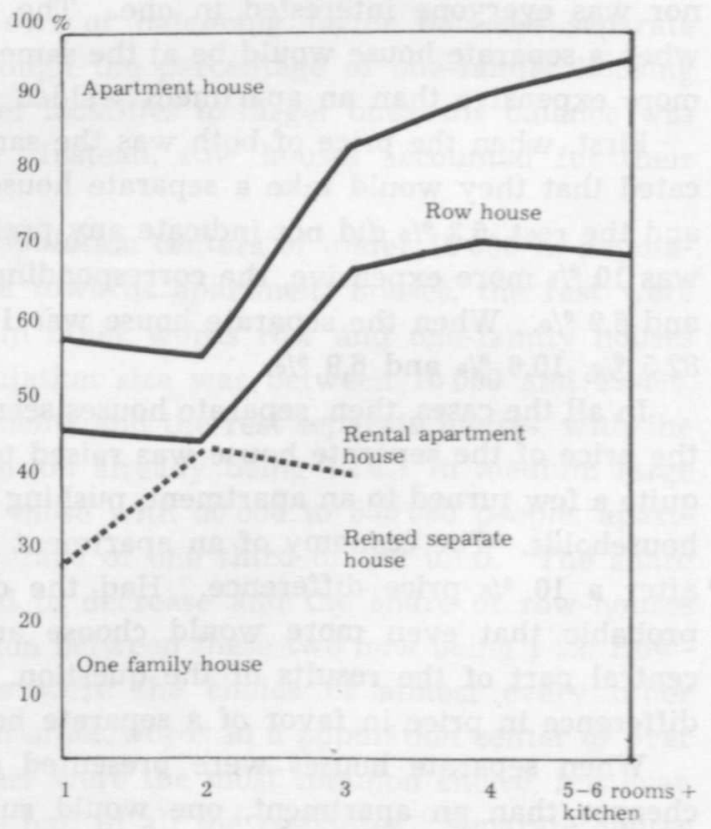


All in all, of those choosing privately-owned houses, less than a fifth would choose a small house, in other words either a one-room house $\left(25-45 \mathrm{~m}^{2}\right)$ or a two-room house $\left(45-60 \mathrm{~m}^{2}\right)$, and of these, the latter alternative was three times the more popular. The most popular house was one with three rooms and a kitchen $\left(55-90 \mathrm{~m}^{2}\right)$, as one third of all the respondents chose this alternative as their goal. However, every fourth household wished for a house that was one room larger, in other words four rooms and a kitchen $\left(80-120 \mathrm{~m}^{2}\right)$, and every tenth wanted a house that was even larger in the number of rooms. However, on the part of those wanting a rented house, the situation was the reverse. Of these, small houses were dominant. Two households out of three was thinking of a one or two room house. Only every sixth had as their goal three rooms and a kitchen, and only every twentieth was thinking of even more rooms.

\section{The number of rooms is more important than the size}

The selection of ideal houses was quite careful when it came to the size of the house. Possibly an important factor for this is that consideration had to be made of the increase of costs for almost every square meter. When the same house was offered with alternatives as to the area, the choice was a small one more often than a large one. This held true for all houses irrespective of the number of rooms. Naturally some preferred larger, other smaller houses, but the latter were more popular, as the average of the area in square meters was clearly less than the average of the area of the alternatives. In the same way it was apparent that the number of rooms was a more important factor than the area. When the same sized houses were offered next to each other, the house with one more room was usually chosen. Thus, a house with three smaller rooms and a kitchen was preferred over one with two large rooms and a kitchen.

The choice of the ideal house's number of room and area, without additional space, already accounted for the bulk of the total cost. Once this choice had been made, one had at the same time set the final price of the house or the final size of the rent to a great extent, even though in extreme cases the additional choices could increase the final costs to double this amount. In any case, it seemed as if, although one was possibly prepared to haggle about the number of square meters of the ideal house, or at least one was very careful in this, this stage set, on the average, two thirds of the final cost.

\section{Little interest in the communal area}

As far as the communal areas go - those outside of the house itself - not many of those who chose an apartment were willing to seek more diversity. 
A clear majority believed that there was no need for an apartment house to have a recreation room, and that the funds that could be set aside for this purpose could be better used elsewhere. Only every fourth of those in favor of private houses, and every sixth of those choosing rented housing disagreed, and were thus prepared to pay for a recreation room in conjunction with their ideal house. Club houses in an apartment house were regarded even more disfavorably than were recreation rooms. Only every sixth of those seeking private ownership, and every thirteenth of those willing to rent believed that a club house was necessary and worth the additional expense.

In the same way, it seems as though a laundry room, and the resultant expenses for those in apartment houses, did not receive unanimous treatment. Of those seeking a privately-owned house, the votes were about even, with the supporters of a laundry room being in the slight majority, but of those seeking a rented apartment, the situation was reversed. Only every third rentpayer favored a laundry room. The rest believed that they could get by without one, or at least were not prepared to pay the resultant additional expense.

\section{The goal is privately-owned housing often at the expense of options}

In speaking of housing goals, a Finn usually thinks in terms of space. Otherwise, he is ready to be satisfied with very little. The different cost factors of housing do not play an equal role. Instead, the variety in values is reflected in the choices themselves just as it is reflected in the choice of a privatelyowned or a rented house.

This difference in values, and the resultant variance in the weight given to different factors in housing became clearly apparent in this study of housing goals, and in certain cases it can be interpreted as an attempt to simplifying housing, something which households in Finland have had little or no opportunity to influence, unless they are building their house themselves. With the exception of rare deluxe houses, houses have been made extremely similar to each other, and in this respect there is little difference between houses produced with private or with government financing. However, the ability of the households to pay as well as their readiness to pay varies, and this can be seen in the results of the choices. When a household is not faced only with a takeit-or-leave-it market, but can also freely choose what type of house it would like, this can not help but be reflected in the results. The requirements placed by the households varied, and what some were prepared to pay for others were not, as the latter were apt to choose the cheapest alternative, even when speaking of large houses.

Even the external and internal sound-proofing of the ideal house was clearly given a different treatment by private owners and tenants. Private owners more often than tenants were satisfied with the usual sound-proofing, even though some of them were prepared to pay for better sound-proofing. 
Of the private-owners, on the average of every fourth, and of the tenants, every third were in favor of better sound-proofing. When it came to exceptionally good sound-proofing, there was little difference, even though the tenants still outnumbered the private owners. The larger the house, the stronger the demand for external sound-proofing. This was true regardless of the fact that better sound-proofing was more expensive for larger houses than for smaller ones.

Internal sound-proofing did not receive much attention, but it was not completely ignored. On the average of every seventh household irrespective of the ownership form was prepared to sacrifice expense for better internal soundproofing. Again, this expense outlet, adding on to the total price or rent, was accepted more readily the larger the house in question. Of the houses consisting of at least five rooms and a kitchen, over a fourth wanted better internal sound-proofing.

\section{Stiff competition between shower and bath}

When washing facilities entered the question, the choices varied widely. One was often prepared to sacrifice options in the bathroom, and these decisions were characterized more by a desire to save than by open-handedness. Therefore, surprisingly often one was prepared to have a shower instead of a bath, as a shower is more economical. These two were very equal competitors, more so than what one could have expected on the basis of the size of the houses.

Naturally, the larger the house, the greater the demands placed on the bathroom, but this relation was not absolute. On the contrary, it was apparent that even some of those that chose the larger houses were willing to have the more simple, and thus the cheaper, of the two alternatives. Thus of those who chose a house of at least five rooms and a kitchen every fourth chose the cheaper alternative, and their bathroom consisted of a shower, a sink and a toilet. As was expected, this alternative was the most common in connection with houses of one room and a kitchen - six out of every ten chose this one.

Most of the alternatives were preferred with painted walls or with plastic covering, and thus not with tiles. The willingness to have tiles increased as expected with the increase in the number of options and the size of the house, even though it never completely shunted aside the cheaper alternatives. It was rather surprising to note that private-owners were less willing to have tiled bathrooms than were tenants, the ratio in this respect being $3: 4$.

Standard equipment in all of the bathroom alternatives was a toilet. Despite this, the households were offered the possibility of a separate toilet. However, relatively few took advantage of this, one third of the private owners and one tenth of the tenants. Again, willingness increased quite clearly, on the part of 
privately-owned houses, with the increase in the size of the houses, but this did not hold true more than to a limited extent with the rented houses.

\section{A private sauna was only added to separate houses}

Opinion was unanimous on the necessity of a sauna, regardless of the type of house and the type of ownership, and one was also prepared to bear the additional expense, but again, different alternatives seemed to have their own supporters. In apartment houses, the present dominating practice of having a sauna for each apartment house and including it in the basic price of the apartments was clear and away the most popular choice, both for privatelyowned and for rented apartments. Of those, however, who chose this alternative, every fifth private owner and ever tenth tenant was prepared to pay for having a swimming pool added on to the sauna. On the other hand, the recent alternative of having a private sauna added to apartments did not attract very many, even though some did choose this. Every thirteenth private apartment owner was dreaming of a private sauna. Not one of the tenants indicated similar dreams.

Those that chose to live in a row house were also given the option of having a sauna for each housing complex, with the resultant savings in cost as in apartment houses, but very few private owners were interested. Only every fifth accepted this alternative, while the rest believed that each house should have its own. On the other hand, every other tenant chose this alternative, thus avoiding the additional cost. Of those dreaming of their own private sauna over half believed that the sauna should have both a dressing and a washing room, and of these every fourth also wanted their own pool.

In the one-family houses, the decisions were made to a great extent along the lines of those in row houses, and the sauna was supposed to include a dressing and a washing room, but on the other hand, one was more reluctant to have a pool. Every fourth wanted a sauna in combination with their bathroom. Of the private owners, every nineteenth, and of the tenants, as many as every third was willing to relinquish a sauna completely.

\section{Stringent kitchen options even in large houses}

With respect to the kitchen options of a range, a sink, and various storage space for cooking utensils and food, the households were given three alternatives, of which the most expensive was over twice the price of the cheapest.

The choices were parallel to the size of the house, but again it was apparent that many households were prepared to be satisfied with very little, this time the tenants even more so than the private owners. Thus, two out of three of the tenants and one out of three of the private owners chose the simplest combination of furnishings and equipment. 


\section{Closets were desired even in houses with one room and a kitchen}

The same economy was apparent also in the storage space outside of the kitchen. It is true that a separate closet was desired, but on the other hand, storage rooms in themselves were rarely a goal, with tenants even less than with private owners. Even of those desiring a privately-owned one room house with a kitchen, every fourth wanted a closet, and the desire for a closet increased evenly with the size of the house, so that almost nine out of ten of those seeking the largest houses also wanted a closet. Of the tenants, on the other hand, almost one half believed that they would use their money in other ways, and would get by without a closet.

Even clothes cupboards were seldom chosen when it was evident that they would add on to the cost. If one started from a level that had two clothes cupboards for each room, then with the exception of the one and two room houses this level was not attained by, on the average, every other household with three rooms and a kitchen or more. In privately-owned two-room houses this level was unattained by every fourth, and with rented two-room houses, every fifth.

Also alternatives indicating an above-average level of demands were indicated. With the exception of one-room houses, most were to be found in the two-room houses and next, surprisingly enough, in houses with three rooms and a kitchen, where every fifth indicated an above-average alternative, in other words as many as in the larger houses.

\section{Every fifth household would get by without a balcony}

The question of the necessity and size of a balcony only affected those living in an apartment house. On the average of every tenth private owner did not choose a balcony at all, and an equal amount ignored the question all together. If one regards these last-mentioned as also having questioned the significance of a balcony, one comes to the conclusion that on the average every fifth household was prepared to relinquish a balcony completely. The result is quite surprising, but is partially supported by the tenants, of whom every fourth immediately rejected a balcony. Furthermore, of the balconies chosen, most were rather small in size.

Most of the balconies were preferred in conjunction with the living room. Every eleventh believed that one should be able to reach the balcony from the bedroom and not from the living room, and there were even a few who believed that the balcony should be connected with the kitchen or in general with the dining area. It seems somewhat strange that as many as one fourth had no idea of where their balcony would be situated. Could it possibly be that they thought that in any case it would be next to the living room, or was there some other reason for refraining from expressing their opinion, according to which one should be able to reach the balcony from somewhere else than 
the ordinary way through the living room? Unfortunately the question remained unanswered.

This, then, was how the households chose. The preferences were certainly not alike; instead, the results varied widely. The different alternatives seemed to find their own supporters without any of them being able to completely shunt aside the others. The results are a clear indication that the household members give different emphasis to the different factors of a house, and if need be they were prepared to give up quite a bit, as long as they were given the opportunity and they could themselves decide. Up to now, they have had very slight opportunities of doing so, as the size of the house has usually dictated the number of options.

The tendency towards economy displayed by the occupants when it came towards choosing options must not, however, be seen as an end in itself. Instead, usually one may regard as the conscious goal the size of the housing. House size seems to be more important than the number of options. One can well say so, as in many cases a house that was smaller than the one chosen would have allowed more options without any change in the total cost.

\section{The willingness to move is largely accumulative and latent}

According to the latest census, carried out in 1970, an average of six households out of every ten lived in a privately-owned house, in other words

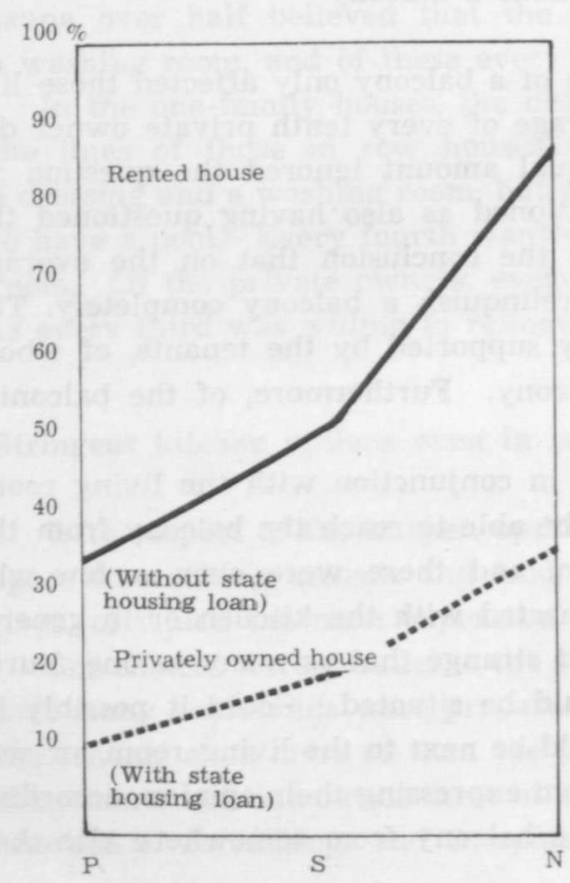

Figure 3. Possession of present house and plans to move.

$\mathrm{P}$ - primary movers

$\mathrm{S}$ - secondary movers

$\mathrm{N}$ - not planning to move 
Figure 4. Present form of housing and plans to move.
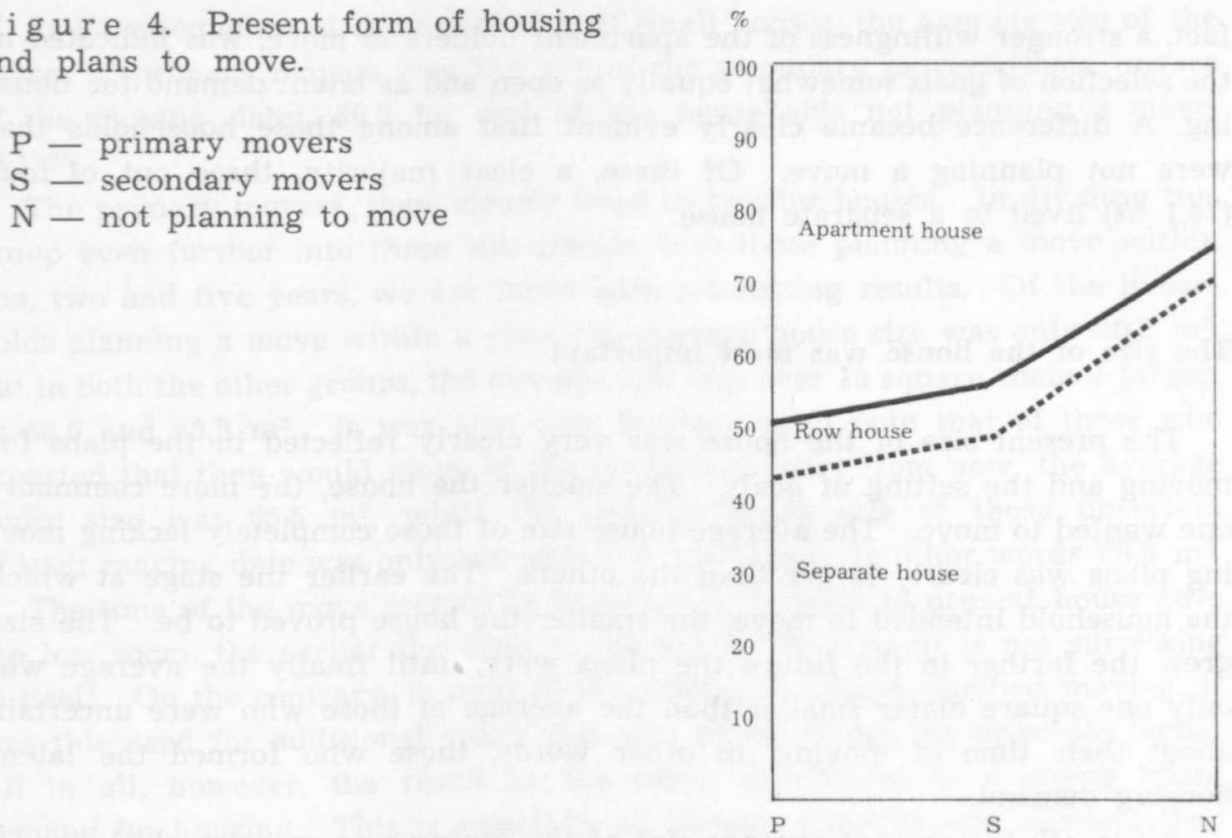

in either a privately owned one-family or row house, or in an apartment in their ownership. The ratio was about the same in this study, but the willingness to move among the households was not divided in the same way, tending clearly towards the tenants. Thus, of the households that had indicated a definite moving date, two thirds $(66,4 \%$ ) lived in a rented house. The latent factors, in other words those households that were not sure of the time they would move, were somewhat equally divided between these two forms of possession, but when it came to those who were not thinking of moving at all, there is a sharp difference. The majority of these lived in a house owned by themselves, and only one seventh $(14,6 \%)$ were tenants. Of all of those living in a privately-owned house, $41,2 \%$ were planning a move, while twice as many - $82,0 \%$ - of the tenants were planning a move.

Thus, it seemed as if renting a house was a strong factor in increasing the willingness to move. Furthermore, the move was definitely not towards another rented house, but usually towards a privately-owned house. It is probably but a coincidence, but even so a noteworthy matter that in indicating their preferences only every seventh chose a rented house, in other words the same number of households that now live in a rented house and were not thinking of moving.

Willingness to move surfaced regardless of the type of house, in other words just as well among one-family, row and apartment houses, but it again seemed to tend towards apartment houses. Of those living in an apartment, as many as three households out of four were planning a move, while only every other household living in a separate house were thinking along the same lines. This 
fact, a stronger willingness of the apartment holders to move, was indicated in the selection of goals somewhat equally as open and as latent demand for housing. A difference became clearly evident first among those households that were not planning a move. Of these, a clear majority, three out of four $(74,1 \%)$ lived in a separate house.

\section{The size of the house was most important}

The present size of the house was very clearly reflected in the plans for moving and the setting of goals. The smaller the house, the more commonly one wanted to move. The average house size of those completely lacking moving plans was clearly larger than the others. The earlier the stage at which the household intended to move, the smaller the house proved to be. The size grew the farther in the future the plans were, until finally the average was only one square mater smaller than the average of those who were uncertain about their time of moving, in other words, those who formed the latent housing demand.

All in all, the present average size of the houses was surprisingly large, in other words exactly ten square meters larger than the average in Finland according to the 1970 census. The census indicated that the average for the entire country was $60,5 \mathrm{~m}^{2}$, while this study, which took place only two years later, resulted in an average of $70,5 \mathrm{~m}^{2}$. Thus, even though the households lived in more spacious quarters than the average Finn, the present houses varied very evidently in their size. Regardless of moving plans, almost half of the households lived in a house that was at the most $60 \mathrm{~m}^{2}$, and even of these an average of every fourth had at the most $35 \mathrm{~m}^{2}$ at their disposal. Of all the households, every eighth had at the most 35 square meters, even though there were as many who had over a hundred square meters. When the households were divided into groups according to their willingness to move, households with at the most $60 \mathrm{~m}^{2}$ at their disposal were to be found in every group, but tended to be concentrated rather clearly among the "primary movers", in other words among those households which are planning a move within the next five years.

Of the primary movers, the house size of every fourth was at the most $35 \mathrm{~m}^{2}$, of the secondary movers (those not sure of when they will move), every eighth had a house which was at the most this size, and of those not planning to move at all, it was only every sixteenth. Of the primary movers, almost two thirds lived in houses $60 \mathrm{~m}^{2}$ or less; of the secondary movers, half; but of those not planning a move, only a third. The differences were quite uniform, and were clearly reflected even in the large houses over $100 \mathrm{~m}^{2}$ in size. Surprisingly enough, even primary movers were to be found in these large houses. Even though at the present every fifteenth household had a house of this size, over $100 \mathrm{~m}^{2}$, the moving plans seemed to be strongly reflected in the present size of the house. 
As a consequence of the dominance of small houses, the average size of the houses of primary movers was $57,9 \mathrm{~m}^{2}$, of the secondary movers (those unsure of the moving date), $66,5 \%$, and of the households not planning a move, $80,1 \%$.

The primary movers, then, clearly lived in smaller houses. In dividing this group even further into three sub-groups, into those planning a move within one, two and five years, we are faced with interesting results. Of the households planning a move within a year, the average house size was only $50,2 \mathrm{~m}^{2}$, but in both the other groups, the average size was over 15 square meters larger, or 65,6 and $65,5 \mathrm{~m}^{2}$. It was also very interesting to note that of those who reported that they would move at the latest five years from now, the average house size was $65,5 \mathrm{~m}^{2}$, while the average house size of those uncertain of their moving date was only one square meter larger, in other words $66,5 \mathrm{~m}^{2}$.

The time of the move seemed to be inversely related to present house size: the less room, the earlier the time of the move. The result is not surprising in itself. On the contrary, in most of the studies that have clarified moving, it was this need for additional space that was shown to be the principle factor. All in all, however, the result at the same time indicates a strong latent demand for housing. This is especially so because those unsure of when they will move and those moving within two years and within five years had, practically speaking, an equal amount of living space, but clearly less living space than those households not planning a move at all had. Thus, the need was clearly recognized, even if the time that it would be satisfied was not defined by quite a few.

Who, then were these goal-setters who said what they would be prepared to pay for in a house, and what they would not?

\section{Moving plans regardless of profession}

With respect to social background, they represented all levels of the 9-level scale. Both the families of professors and of unskilled workers were dreaming of moving. However, when it came to the extremes of this scale, there were about as many planning a move as there were remaining in their present house. The bulk of the moving willingness was apparent in the hardto-define and multi-tiered middle level, which possibly begins with bank directors and those with master's degrees and extends to metal turners and telephone mechanics. Even though already among these, there were fewer planning a move among the lower levels, clear differences did not come apparent until below these levels, where we find, among others, mailmen and auto mechanics' assistants.

Thus, moving plans were to be found in all the social levels, and not just among the higher ones. With the exception of the lowest and the highest, the distribution was quite similar to the population structure of the entire country, 
and pressure towards moving was apparent among the households regardless of the social level. However, the higher levels were planning a move more often than the lower levels, and they also seemed to have better possibilities of realizing their plans.

In using the rough three-level division of social stratification, of all those households belonging to the I level, every fourth was planning on moving within five years, but of those in the II level, it was only every fifth, and in the III level, only every tenth. The differences between these levels is reflected in a similar direction also among those households not sure of when they will move. Of those in the I level, every fourth was not planning a move at all, in the II level, every third, and in the III level, every second.

Thus, regardless of the social strata, there also seemed to be a strong latent demand for housing in all the households. In other words, one was more or less dissatisfied with the present house, and one was planning on moving without having yet set a definite time. It could have been readily expected that this latent demand was blocked up by financial resources, but surprisingly enough, the research results do not seem to support this idea. It is true that the income of the households at the top of the social stratification was over four times that at the bottom, and the income diminishes evenly as one goes down the scale, but on the other hand, the income within each class was the same regardless of whether the household was moving or not. Thus, at least as far as income goes, those who were planning a move were not in an exceptional position. 